DOI: $10.5604 / 01.3001 .0012 .8046$

\title{
MODIFICATIONS OF MAXIMUM POWER POINT TRACKING P\&O METHOD FOR PHOTOVOLTAIC PANEL
}

\author{
Piotr Kozierski ${ }^{1,2}$, Adam Owczarkowski ${ }^{3}$, Marcin Lis ${ }^{3}$, Dariusz Horla ${ }^{2}$ \\ ${ }^{1}$ Poznan University of Technology, Faculty of Computing, Institute of Automation and Robotics, Division of Signal Processing and Electronic Systems \\ ${ }^{2}$ Poznan University of Technology, Faculty of Electrical Engineering, Institute of Control, Robotics and Information Engineering \\ ${ }^{3}$ Spirvent sp. z o.o., Pokrzywno street 4A, 61-315 Poznan
}

Abstract. Perturbation and Observe method for maximum power point tracking is presented in this paper. Three method modifications have been proposed, which allow satisfying tracking efficiency, even for very fast and noisy irradiance changes.

Keywords: tracking, photovoltaic panels, perturbation and observe, MPPT

\section{MODYFIKACJE METODY P\&O ŚLEDZENIA MAKSYMALNEGO PUNKTU MOCY DLA PANELU FOTOWOLTAICZNEGO}

\begin{abstract}
Streszczenie. W artykule przedstawiono metodę zaburzania i obserwacji P\&O do śledzenia maksymalnego punktu mocy. Zaproponowano trzy modyfikacje metody, dzięki którym efektywność śledzenia jest zadowalająca, nawet dla bardzo szybkich oraz zaszumionych zmian irradiancji.
\end{abstract}

Słowa kluczowe: śledzenie, panele słoneczne, zaburzanie i obserwacja, MPPT

\section{Introduction}

Thanks to Maximum Power Point Tracking (MPPT) methods it is possible to obtain a maximum power of device under given conditions. These methods are used mainly when device model is too complex, when too many variables should be taken into account (including cases in which these variables are difficult to measure), and also when satisfying results must be obtained with relatively low computing costs. MPPT methods are applicable among others in energy generation from renewable energy sources, e.g. from wind $[1,13]$ or sunlight $[10,11]$.

There are many different MPPT methods, but Perturbation and Observe (P\&O) is the most often used method, mainly due to the simplicity of implementation while achieving quite good tracking results [2], also for changing weather conditions. This method is described in Section 1 in more detail.

The all methods one can divide into direct and indirect [14]. The indirect methods require some knowledge about working device, its characteristics, et cetera. Therefore, they require a certain "initial work", however the algorithms are in fact quite simple and fast. Short Circuit Current method, Open Circuit Voltage method, Curve Fitting method and Look-up Table method belong to such algorithms.

The second group of techniques includes methods, which do not require any additional information about used devices, and moreover, they can work in variable climatic conditions. This group includes such algorithms as Differential method, previously mentioned P\&O method, Conductance Incremental method $[3,6]$ and Forced Oscillations method.

The additional subgroup - Hill Climbing Techniques - was specified in [4]. In these methods the device operation point is shifted in the direction, which increases the device output power. $\mathrm{P} \& \mathrm{O}$ and Conductance Incremental methods belong to this techniques.

A separate algorithms group are methods, which based on the neural networks, fuzzy logic [12] or genetic algorithms [8].

In the presented work the authors are focused on the $\mathrm{P} \& \mathrm{O}$ method and few modifications to this MPPT algorithm were proposed.

In Section 1 P\&O method principle of operation was described. In the second section the model of photovoltaic panel was described - based on this model further simulations were performed. The third and fourth sections contain simulation results and descriptions of all modifications. In the last section the whole paper was summarized.

\section{Perturbation and Observe (P\&O) method}

As it was mentioned earlier, $\mathrm{P} \& \mathrm{O}$ method is very commonly used. The algorithm is easy to implement - in subsequent steps, the voltage of PV generator is forced to change, and then it is observed whether the power of the generator has increased or decreased [14]. If the power has increased, voltage changes are continued in the same direction, and if the power has decreased, the changes direction should be set to the opposite.

The algorithm, which appears in literature [7,9] and presents operation principle of the $\mathrm{P} \& \mathrm{O}$ method is presented in Fig. 1, whereas the authors propose a pseudocode (see Algorithm 1), for better readability.

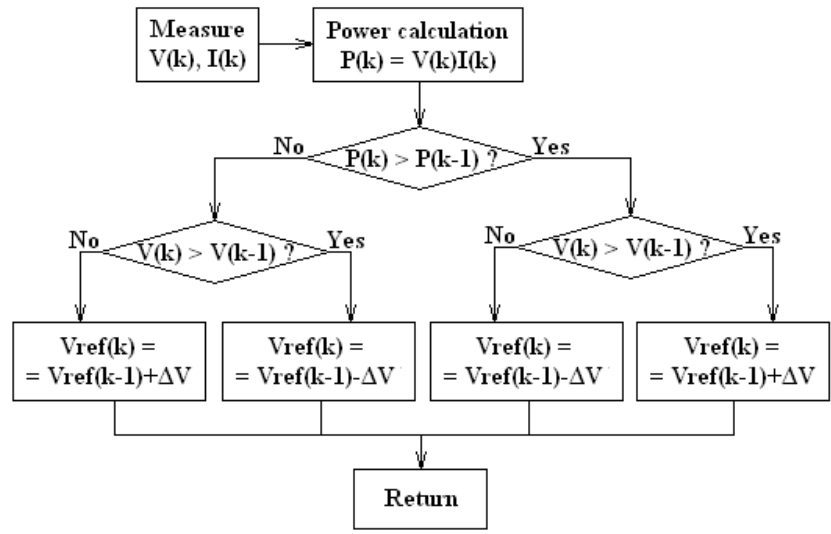

Fig. 1. Scheme of operation principle of the $P \& O$ method

Algorithm 1 - Principle of operation of the P\&O method

1. Set the voltage changes direction $d_{i r}=1$ and changes step $\Delta V$.

2. Measure voltage $V^{(k)}$ and current $I^{(k)}$ at $k$-th time step. Calculate power $P^{(k)}=V^{(k)} \cdot I^{(k)}$

3. If $P^{(k)}<P^{(k-1)}$, then $d_{i r}=-d_{i r}$.

4. $V_{\text {ref }}^{(k)}=V_{\text {ref }}^{(k-1)}+d_{i r} \cdot \Delta V$.

5. Go to step 2.

However, this technique has two disadvantages - oscillations near the optimal value and low tracking quality, when irradiance (power of light per unit area $\left[\mathrm{W} / \mathrm{m}^{2}\right]$ ) grows rapidly [2].

In the paper [9] the modified P\&O method was presented. In this algorithm every second step the voltage is not changed and the power change resulting from changes in atmospheric 
conditions is checked. In the next step it is decided if the changes direction is proper. Also the second modification was proposed, in which this verification of direction is made less frequently, every third step.

In the work [7] authors proposed modification, which introduces hysteresis and step of changes autotuning mechanism. Also in the article [2] one has focused on the adaptation varieties of $\mathrm{P} \& \mathrm{O}$, which allow changes of the step $\Delta V$ size.

In this paper the authors also proposed few modifications of the P\&O method and thanks to this the improvement of MPPT method was obtained.

\section{Model of Photovoltaic Panel}

The model of photovoltaic panel (PV), which was used in the research, can be described by the equations [2]

$$
\begin{gathered}
I=I_{P V} \cdot N_{p}-I_{D 1}-I_{D 2}-\frac{V+N \cdot I \cdot R_{s}}{N \cdot R_{p}}, \\
I_{D 1}=I_{d 1} \cdot N_{p} \cdot \exp \left(\frac{V+N \cdot I \cdot R_{s}}{a_{1} \cdot V_{T 1} \cdot N_{s}}\right), \\
I_{D 2}=I_{d 2} \cdot N_{p} \cdot \exp \left(\frac{V+N \cdot I \cdot R_{s}}{a_{2} \cdot V_{T 2} \cdot N_{s}}\right), \\
I_{P V}=\left(I_{P V_{-} S T C}+K_{I}\left(T-T_{S T C}\right)\right) \cdot \frac{G}{G_{S T C}}, \\
I_{d 1}=I_{d 2}=\frac{I_{s c}+K_{I}\left(T-T_{S T C}\right)}{\exp \left(\frac{V_{o c}+K_{V}\left(T-T_{S T C}\right)}{V_{T}}\right)-1}, \\
N=N_{s} / N_{p},
\end{gathered}
$$

where: $I-\mathrm{PV}$ current, $V$ - PV voltage, $N_{p}$ - number of panels connected in parallel, $N_{s}$ - number of panels connected in series, $R_{s}$ - series resistance, $R_{p}$ - parallel resistance, $a_{1}$ and $a_{2}$-ideality factor for the first and second diode, $V_{T}$ - thermal voltage of the diodes, $G$ - irradiance, $T$ - temperature, $K_{I}$ - current temperature coefficient, $I_{s c}$ - short circuit current, $V_{o c}$ - open collector voltage, $K_{V}$ - voltage temperature coefficient, $S T C$ - refers to values in Standard Test Conditions.

As one can easily see, after substitutions, calculated in (1) PV current value is also on the right side of the equation and in power. To solve this equation one should use W Lambert function or any numeric techniques.

The characteristics, which were obtained from the model of photovoltaic panel were presented in Fig. 2-3. The results of the studies presented later in the article were performed using this model.

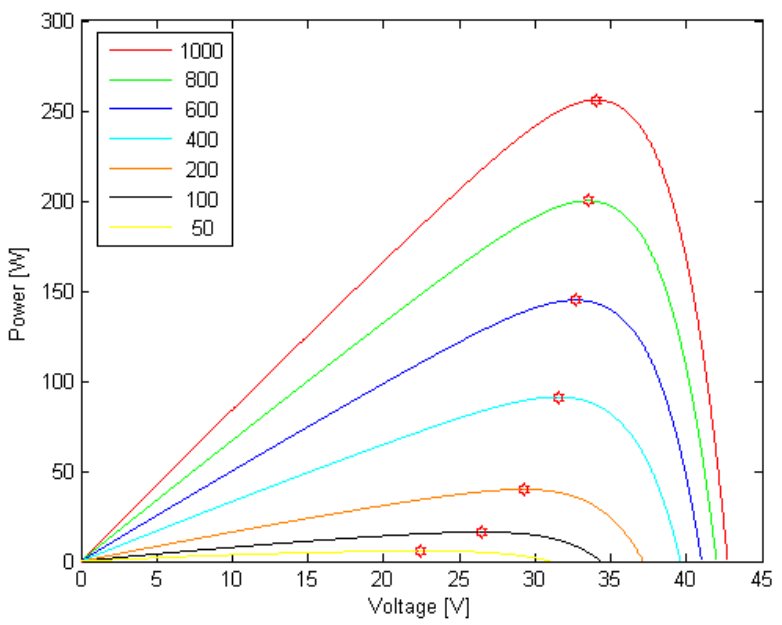

Fig. 2. Characteristics of power from voltage for different irradiance values; points in which power value is the highest are marked by red stars

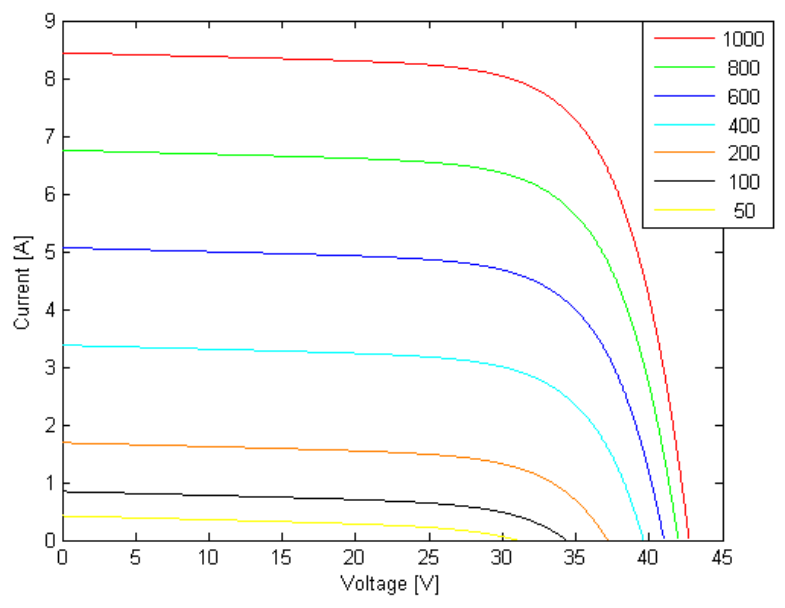

Fig. 3. Characteristics of current from voltage for different irradiance values

\section{Performed simulations}

It was assumed in the performed simulations that reference voltage $V^{(k)}$ ref is equal to the measured value $V^{(k+1)}$, and current $I^{(k)}$ is calculated based on the equations (1-6). Thanks to this approach it was possible to focus entirely on the $\mathrm{P} \& \mathrm{O}$ algorithm and on the proposed modifications.

The theoretical course of irradiance was proposed in the studies

$$
G=500 \sin \left(\frac{t \pi}{2}\right)+550\left[\frac{W}{m^{2}}\right]
$$

and also theoretical course of temperature

$$
T=57.5 \sin \left(\frac{t \pi}{30}\right)+12.5\left[{ }^{\circ} \mathrm{C}\right]
$$

for time t varying from 0 to 60 seconds. Based on the equations (1-6) the waveform of maximum power point was obtained - see Fig. 4. As one can see, a fifteenfold brightening and dimming of sunlight within a minute was assumed. It means that the time between minimum and maximum irradiance is only 2 seconds.

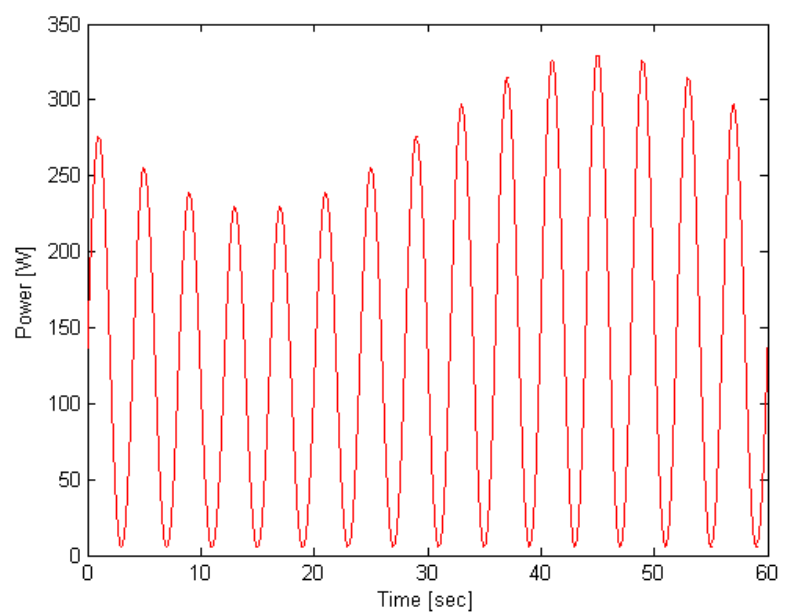

Fig. 4. The waveform of the maximum power point for a given model and weather conditions

To compare the quality of MPPT methods the efficiency was calculated $[2,5,6]$

$$
\eta=\frac{\int P d t}{\int P_{\max } d t}=\frac{\sum_{k=1}^{N_{k}} P^{(k)}}{\sum_{k=1}^{N_{k}} P_{\max }^{(k)}},
$$

where $N_{k}$ is number of time steps in whole simulation (the length of time step was set on $0.5 \mathrm{~ms}$, what gives 120 thousands of time steps during 60 seconds of simulation), and $P^{(k)}$ max is a maximum 
power, which can be obtained from PV in given weather conditions at $k$-th time step.

It was assumed that the time step of MPPT method is equal to $2.5 \mathrm{~ms}$, the same time was proposed in [9]. Between subsequent MPPT steps it was assumed that voltage is constant and equal to the last calculated value.

The simulation results for conditions described above, with changes step $\Delta V=0.05[\mathrm{~V}]$, are presented in Fig. 5, and the efficiency was equal to $\eta=0.831$ (and calculating from the second period of irradiance, to ignore the effect of the initial power increase, $\eta=0.8454$ was obtained).

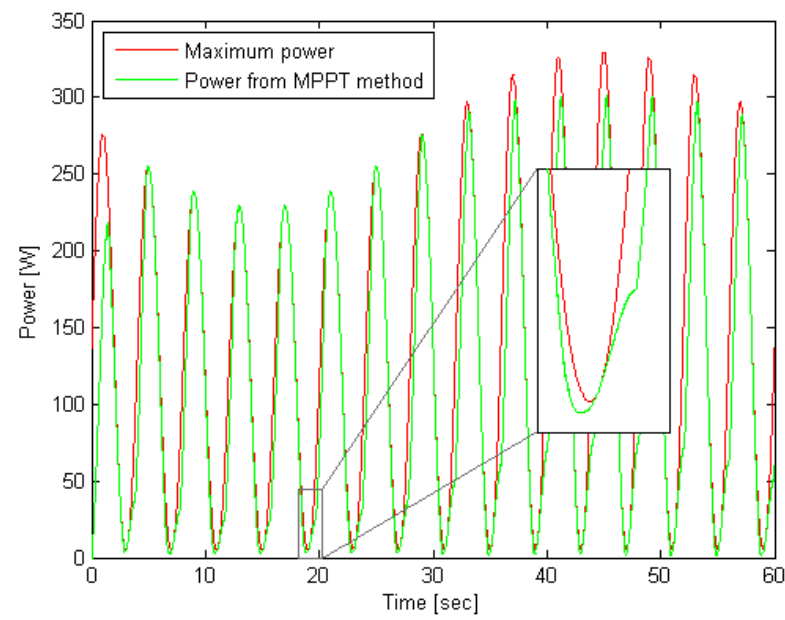

Fig. 5. Characteristics of power in time - simulation results of the basic $P \& O$ method (Algorithm 1); obtained efficiency was equal to $\eta=0.831(\eta=0.84543$ calculating from the second period)

\section{Modifications of $P \& O$ method and obtained results}

In the Fig. 5 one can see enlarged chart fragment. It can be conclude that the highest power loses in basic $\mathrm{P} \& \mathrm{O}$ method (Algorithm 1) are during increase of the irradiance - power obtained from MPPT method grows slower and slower, and at some point "something switches" and rapid growth starts. What is going on? To the "switch" moment the voltage still decreases, because voltage reduction by $\Delta V$ has lower impact on obtained power than the irradiance $G$ growth.

Accordingly, the modification was proposed - every period of time (specifically it was proposed every $50 \mathrm{~ms}$, i.e. every 20 steps of MPPT method) the change of voltage is tried in the opposite direction. If the power growth in subsequent step will be higher than in current step, then the direction will be changed to the opposite. And if no - voltage changes should be continued in the right direction, but the wrong attempt should be made up by triple $\Delta V$ step. Remaining 19 MPPT steps should be carried out according to the standard $\mathrm{P} \& \mathrm{O}$ method. Principle of operation is presented by pseudocode in Algorithm 2.

\section{Algorithm 2 - The first $\mathrm{P} \& \mathrm{O}$ modification}

1. Set the voltage changes direction $d_{i r}=1$, multiplicity $d_{\text {mult }}=1$ and changes step $\Delta V=0.05$.

2. Measure voltage $V^{(k)}$ and current $I^{(k)}$ at $k$-th time step. Calculate power $P^{(k)}=V^{(k)} \cdot I^{(k)}$.

3. If modulo $(k / 20)==0$, then perform step 4 :

4. If $P^{(k)}>P^{(k-1)}$ and $P^{(k)}-P^{(k-1)}>P^{(k-1)}-P^{(k-2)}$, then $d_{i r}=-d_{i r}$.

4a. Otherwise $d_{\text {mult }}=3$.

5. If modulo $(k / 20)==19$, then $V_{\text {ref }}^{(k)}=V^{(k-1)}{ }_{\text {ref }}-d_{i r} \cdot \Delta V$.

5a. Otherwise perform steps 6-7:

6. If modulo $(k / 20) \neq 0$ and $P^{(k)}<P^{(k-1)}$, then $d_{i r}=-d_{i r}$.

7. $V_{\text {ref }}^{(k)}=V_{\text {ref }}^{(k-1)}+d_{i r} \cdot \Delta V \cdot d_{m u l t}$.

8. Set $d_{\text {mult }}=1$; go to step 2 .

Using algorithm with the first modification the efficiency $\eta=0.967$ was obtained $(\eta=0.988$ calculating from the second period).
Afterwards, fragment before minimum value in Fig. 5 was improved. To understand, where is the problem, the voltage waveform was checked - it is shown in Fig. 6.

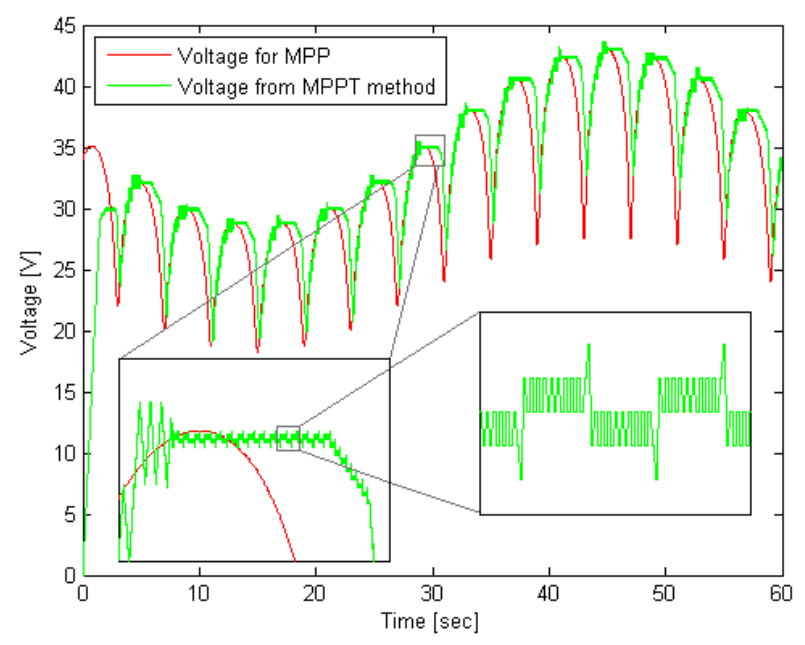

Fig. 6. Characteristics of voltage in time - simulation results of $P \& O$ method with the first modification (Algorithm 2); it was obtained $\eta=0.967(\eta=0.988$ calculating from the second period)

As one can see, the changes direction $d_{i r}$ has opposite sign in almost every MPPT step. Every 20 MPPT steps one can see impact of the first modification; however, after that $d_{i r}$ changes are continued. It is because of the power decrease, which is caused by the irradiance decreasing. And the impact of irradiance is much bigger than the impact of voltage changes.

Therefore, the second modification of $\mathrm{P} \& \mathrm{O}$ method was proposed - it checks whether change of direction occured 5 or more times in a row. If yes, then it is checked how much the power was decreased in the latest steps. If alternately there is higher and lower decrease, the direction which provides lower decrease is taken and multiplicity is set on $d_{m u l t}=3$. In such a way voltage decreasing is forced even during irradiance decreasing. Precise operation of principle was presented in Algorithm 3.

\section{Algorithm 3 - The second $\mathrm{P} \& \mathrm{O}$ modification}

1. Set the voltage changes direction $d_{i r}=1$, multiplicity $d_{\text {mult }}=1$, changes counter $d_{z m}=0$ and changes step $\Delta V=0.05$.

2. Measure voltage $V^{(k)}$ and current $I^{(k)}$ at $k$-th time step. Calculate power $P^{(k)}=V^{(k)} \cdot I^{(k)}$.

3. If $\operatorname{modulo}(k / 20)==0$, then perform step 4 :
4. If $P^{(k)}>P^{(k-1)}$ and $P^{(k)}-P^{(k-1)}>P^{(k-1)}-P^{(k-2)}$, then $d_{i r}=-d_{i r}$ and $d_{z m}=d_{z m}+1$.

4a. Otherwise $d_{m u l t}=3$ and $d_{z m}=0$.

5. If modulo $(k / 20)==19$, then $V^{(k)}$ ref $=V^{(k-1)}{ }_{\text {ref }}-d_{i r} \cdot \Delta V$.

5a. Otherwise perform steps 6-11:

6. If $d_{z m}<5$, then perform steps 7-8:

7. If modulo $(\mathrm{k} / 20) \neq 0$ and $P^{(k)}<P^{(k-1)}$, then $d_{i r}=-d_{i r}$ and $d_{z m}=d_{z m}+1$.

7a. Otherwise $d_{z m}=0$

8. $V_{\text {ref }}^{(k)}=V_{\text {ref }}^{(k-1)}+d_{i r} \cdot \Delta V \cdot d_{\text {mult }}$.

6a. Otherwise perform steps $9-11$ :

9. If $P^{(k-1)}-P^{(k-2)}>P^{(k-2)}-P^{(k-3)}$ and $P^{(k-1)}-P^{(k-2)}>P^{(k-4)}-P^{(k-5)}$ and $P^{(k-3)}-P^{(k-4)}>P^{(k-2)}-P^{(k-3)}$ and $P^{(k-3)}-P^{(k-4)}>P^{(k-4)}-P^{(k-5)}$, then $d_{i r}=-d_{i r}$ and $d_{\text {mult }}=3$.

10. If $P^{(k-1)}-P^{(k-2)}<P^{(k-2)}-P^{(k-3)}$ and $P^{(k-1)}-P^{(k-2)}<P^{(k-4)}-P^{(k-5)}$ and $P^{(k-3)}-P^{(k-4)}<P^{(k-2)}-P^{(k-3)}$ and $P^{(k-3)}-P^{(k-4)}<P^{(k-4)}-P^{(k-5)}$, then $d_{\text {mult }}=3$.

11. $V_{\text {ref }}^{(k)}=V_{\text {ref }}^{(k-1)}+d_{i r} \cdot \Delta V \cdot d_{m u l t}$ and $d_{z m}=0$.

12 . Set $d_{\text {mult }}=1$; go to step 2 .

Using $\mathrm{P} \& \mathrm{O}$ algorithm with the second modification, the efficiency $\eta=0.9782$ was obtained (calculating from the second period $\eta=0.9993)$. It can be seen that algorithm with modifications works very well; however, it is not robust for any device noise or slight (in comparison to the general changes) 
irradiance fluctuations. It is due to the fact that algorithms are based on values differences in specific time moments. If any "noise" will be higher than changes step $\Delta V$, then all these modifications will be have insignificant influence on obtained quality of tracking.

Therefore, the irradiance waveform was changed - the Gauss noise was added

$$
G=500 \sin \left(\frac{t \pi}{2}\right)+550\left[\frac{W}{m^{2}}\right]+N\left(0, \sigma^{2}\right)
$$

and the third $\mathrm{P} \& \mathrm{O}$ modification was proposed. This modification change the $\Delta V$ step based on the power from last $50 \mathrm{~ms}$ (21 MPPT steps). Specifically, this value should be equal to

$$
\Delta V=\max \left[0.05 \cdot\left(\log _{10}\left(\operatorname{var}\left[P^{(k-20)}, \ldots, P^{(k)}\right]\right)+3\right) ; 0.05\right] .
$$

The operation principle was proposed in Algorithm 4.

\section{Algorithm 4 - The third P\&O modification}

1. Set the voltage changes direction $d_{i r}=1$, multiplicity $d_{\text {mult }}=1$, changes counter $d_{z m}=0$, changes step $\Delta V=0.05$ and step of the last calculation of changes step $k_{\Delta V}=0$.

2-11. Steps 2-11 are identical as in Algorithm 3.

12. If $k>100$ and $\left|P^{(k-20)}-P^{(k)}\right|<0.2$ and $k-k_{\Delta V}>1000$ and $V^{(k)}>10$, then perform steps 13-15:

13. $k_{\Delta V}=k$.

14. Calculate power variance $v_{P}$ from $P^{(k-20)}$ to $P^{(k)}$.

15. If $v_{P}<0.01$, then $\Delta V=0.05$.

15a. Otherwise $\Delta V=0.05 \cdot\left(\log _{10}\left(v_{P}\right)+3\right)$.

16. Set $d_{\text {mult }}=1$; go to step 2 .

As one can see few conditions were introduced, among others one which does not allow to change $\Delta V$ more than once every half a second. The efficiency of all algorithms for different noise standard deviations $\sigma$ is presented in Table 1

Table 1. Efficiency results of all presented MPPT methods for different noise variance (results in brackets were calculated from the second period)

\begin{tabular}{|c|c|c|c|c|}
\hline$\sigma$ & Algorithm 1 & Algorithm 2 & Algorithm 3 & Algorithm 4 \\
\hline 0 & $0.8310(0.8454)$ & $0.9670(0.9880)$ & $0.9782(0.9993)$ & $0.9783(0.9993)$ \\
\hline 0.2 & $0.8860(0.9020)$ & $0.9636(0.9846)$ & $0.9736(0.9950)$ & $0.9739(0.9952)$ \\
\hline 1 & $0.9628(0.9855)$ & $0.9641(0.9866)$ & $0.9665(0.9890)$ & $0.9746(0.9957)$ \\
\hline 3 & $0.9450(0.9746)$ & $0.9451(0.9745)$ & $0.9420(0.9730)$ & $0.9709(0.9944)$ \\
\hline 5 & $0.9181(0.9534)$ & $0.9260(0.9599)$ & $0.9310(0.9653)$ & $0.9675(0.9909)$ \\
\hline 10 & $0.8730(0.9118)$ & $0.8799(0.9177)$ & $0.8734(0.9136)$ & $0.9514(0.9847)$ \\
\hline
\end{tabular}

\section{Summary}

The operation principle of P\&O MPPT method was presented in the article, and also three $\mathrm{P} \& \mathrm{O}$ modifications were proposed thanks to them algorithm has a good tracking quality, even at rapid and noisy irradiance changes.

\section{Acknowledgements}

Research was cofinanced by The National Centre for Research and Development as part of the Intelligent Development operational program 2014-2020, operation 1.1/suboperation 1.1.1, application number POIR.01.01.01-00-0468/17.

\section{References}

[1] Abdullah M. A., Yatim A. H. M., Tan C. W.: A study of maximum power poin tracking algorithms for wind energy system. In Clean Energy and Technology (CET), 2011 IEEE First Conference, 321-326.

[2] Ahmed J., Salam Z.: A modified P\&O maximum power point tracking method with reduced steady-state oscillation and improved tracking efficiency. IEEE Transactions on Sustainable Energy 4/2016, 1506-1515.

[3] Chung T. M., Daniyal H., Sulaiman M. H., Bakar M. S. Comparative study of $\mathrm{P} \& \mathrm{O}$ and modified incremental conductance algorithm in solar maximum powe point tracking. In 4th IET Clean Energy and Technology Conference (CEAT) $11 / 2016,5$.

[4] Gaur P., Verma Y. P., Singh P.: Maximum power point tracking algorithms for photovoltaic applications: A comparative study. In Recent Advances in Engineering \& Computational Sciences (RAECS), 2nd International Conference $12 / 2015,5$.
[5] Hohm D. P., Ropp M. E.: Comparative study of maximum power point tracking algorithms. Progress in photovoltaics: Research and Applications 1/2003, 47-62 [doi: 10.1002/pip.459].

[6] Hussein K. H., Muta I., Hoshino T., Osakada M.: Maximum photovoltaic power tracking: an algorithm for rapidly changing atmospheric conditions. IEE Proceedings-Generation, Transmission and Distribution 1/1995, 59-64.

[7] Jung Y., So J., Yu G., Choi J.: Improved perturbation and observation method (IP\&O) of MPPT control for photovoltaic power systems. In Photovoltaic Specialists Conference, Conference Record of the Thirty-first IEEE 01/2005, $1788-1791$.

[8] Lasheen M. A., Bendary F. M., Sharaf M., El-Zoghby H. M.: Maximum power point tracking of a wind turbine driven by synchronous generator connected to an isolated load using genetic algorithm. In Smart Grid Conference (SASG), Saudi Arabia 12/2014, 1-9.

[9] Liu C., Wu B., Cheung R.: Advanced algorithm for MPPT control of photovoltaic systems. In Canadian Solar Buildings Conference, Montreal 08/2004, 20-24.

[10] More D. N., Naik A. V., Kumar V. C.: Maximum power point using P\&O technique for photovoltaic system. In Technological Innovations in ICT for Agriculture and Rural Development (TIAR) 04/2017, 134-137.

[11] Seyedmahmoudian M., Horan B., Rahmani R., Maung Than Oo A., Stojcevski A.: Efficient photovoltaic system maximum power point tracking using a new technique. Energies 147(9)/2016, 1-18.

[12] Surma P.: Porównanie metod MPPT paneli fotowoltaicznych (P\&O, IC, Fuzzy Logic) w środowisku Matlab Simulink. Przegląd Elektrotechniczny 1/2014, 66-69.

[13] Van T. L., Nguyen D. Q., Duy V. H., Nguyen H.: Fast Maximum Power Point Tracking Control for Variable Speed Wind Turbines. In International Conference on Advanced Engineering Theory and Applications 12/2017, 821-829.

[14] Zaremba A., Rodziewicz T., Wacławek M.: Algorytmy śledzenia punktu mocy maksymalnej (MPPT) w systemach fotowoltaicznych. Proceedings of ECOpole 2/2012, 805-810 [doi: 10.2429/proc.2012.6(2)112].

\section{M.Sc. Eng. Piotr Kozierski \\ e-mail: piotr.kozierski@gmail.com}

Third year full-time third degree student in Poznan University of Technology, Faculty of Computing. Is interesting in normal and whispery speech recognition using Kaldi toolkit. Additionally research area is associated with state estimation of nonlinear, multivariable plants and with particle filters.

ORCID ID: 0000-0001-8777-6132

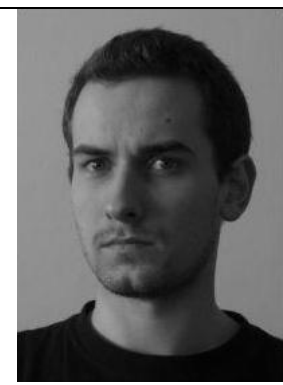

Ph.D. Eng. Adam Owczarkowsk

e-mail: adam.owczarkowski@spirvent.pl

Ph.D. in control and robotics from 2017 (at Poznan University of Technology) He conducted research on dynamics of two-wheeled vehicles with reaction wheel. Is interested in scientific research project realization associated with modern theory of nonlinear systems control, informatics and robotics.

ORCID ID: 0000-0002-1398-6484

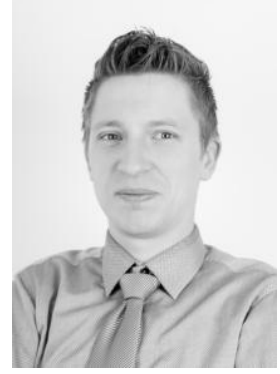

M.Sc. Eng. Marcin Lis

e-mail: marcin.lis@spirvent.pl

Over the years, he worked for such companies as Energo and Spirvent in positions related to research and development activities. Earlier, he devoted himself to scientific research on the use of neural networks in control.

ORCID ID: 0000-0001-7324-2383

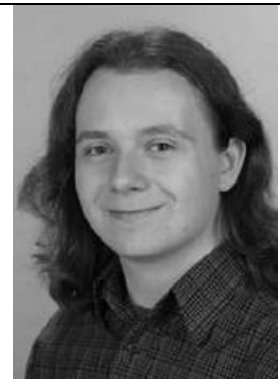

\section{D.Sc. Eng. Dariusz Horla}

e-mail: dariusz.horla@ put.poznan.pl

Is working in Institute of Control, Robotics and Information Engineering at Poznan University of Technology (PUT). Ph.D in 2005, Post-doctoral degree in 2013 in technical sciences on Faculty of Electrical Engineering at PUT. His area of interest is windup compensation, optimal control, adaptive control, optimization theory and linear matrix inequalities.

ORCID ID: 0000-0002-9456-6704

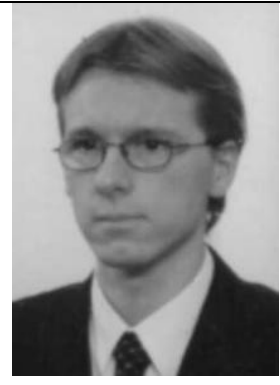

otrzymano/received: 14.09.2018

przyjęto do druku/accepted: 15.12 .2018 